\title{
Literacy as a pathway between schooling and health-related communication skills: a study of Venezuelan mothers
}

\section{Citation}

Schnell-Anzola, Beatrice, Meredith L. Rowe, and Robert A LeVine. 2005. Literacy as a pathway between schooling and health-related communication skills: a study of Venezuelan mothers. International Journal of Educational Development 25, no. 1:19-37

\section{Published Version}

doi:10.1016/j.ijedudev.2004.05.002

\section{Permanent link}

http://nrs.harvard.edu/urn-3:HUL.InstRepos:13041211

\section{Terms of Use}

This article was downloaded from Harvard University's DASH repository, and is made available under the terms and conditions applicable to Other Posted Material, as set forth at http:// nrs.harvard.edu/urn-3:HUL.InstRepos:dash.current.terms-of-use\#LAA

\section{Share Your Story}

The Harvard community has made this article openly available.

Please share how this access benefits you. Submit a story.

\section{Accessibility}




\title{
Literacy as a pathway between schooling and health-related communication skills: a study of Venezuelan mothers
}

\author{
Beatrice Schnell-Anzola $^{a}$, Meredith L. Rowe ${ }^{\text {b,* }}$, Robert A. LeVine \\ ${ }^{a}$ Harvard Graduate School of Education \\ ${ }^{\mathrm{b}}$ University of Chicago, 5848 S. University Ave (G317), Chicago, IL 60637, USA
}

\begin{abstract}
This article addresses the mechanisms by which women's schooling might affect the survival and health of their children. A theoretical model is proposed in which academic literacy skills serve as a pathway between formal schooling and maternal health-related behaviors. The model is tested through multivariate analyses of interview and literacy data from 161 mothers in a poor, urban community in Venezuela. Results show that the academic literacy skills women learned in school and retained into adulthood, predict their health-related communication skills above and beyond the amount of schooling they received. The importance of female schooling in developing countries is discussed.
\end{abstract}

(C) 2004 Elsevier Ltd. All rights reserved.

Keywords: Women's education; Literacy; Language skills; Health activities; Health behavior; Venezuela

\section{Introduction}

Women's formal education is associated with the survival and health of their children in many contemporary societies, but the processes involved have remained obscure and are only beginning to be explored (Diamond et al., 1999). This article addresses the question of whether there might be a literacy pathway from schooling to health, operating through the health-related communication skills of mothers. We review relevant literatures in demography and literacy research, build a

\footnotetext{
*Corresponding author. Tel.: (773)-834-1447.

E-mail address: rowemer@uchicago.edu (M.L. Rowe).
}

plausible theoretical model and test this model with a sample of 161 mothers of children under five from a poor urban area in Caracas, Venezuela. We chose the barrio $^{1}$ of La Silsa for our study because the level of schooling of its female population varied greatly, ranging from illiterate to university level studies, a range not commonly found within the same community in other developing countries. This large variation provided us with the unique opportunity to explore how mothers with various levels of education,

\footnotetext{
${ }^{1}$ In Venezuela, barrio refers to a low-SES neighborhood that formed after the massive migration to the cities beginning in the late 1950s.
} 
literacy skills, and health practices might make use of the same, often inadequate, community health services.

\subsection{Literacy in population and development studies}

In analyses of the demographic impact of women's schooling, there are sharply contrasting positions concerning literacy. In one set of analyses, it is simply presumed that literacy is a link between school experience and reproductive behavior. The terms "literacy", "education", "schooling" and "educational attainment" are used interchangeably, and literacy is indirectly assessed through a proxy measure based on school attendance or a brief self-report. The question of whether women actually acquire literacy skills in school and retain them into their childbearing years is not addressed or even explicitly considered (e.g., Jain and Nag, 1986; Mayer, 1999; UNICEF, 1998).

In another set of analyses, the question of whether female literacy might be a pathway to reproductive change is explicitly considered but rejected. The basic argument is that, in the absence of evidence to the contrary, it is more plausible to believe that schools in developing countries influence the social attitudes of girls (leading them to become more ambitious, assertive or autonomous) than that the schools effectively transmit curricular skills like literacy (Caldwell, 1994; Cleland, 1990; Jejeebhoy, 1995; Kasarda et al., 1986). A specific point made against the plausibility of a curricular pathway of influence is that the relationships between maternal schooling and child mortality are consistent across all levels of schooling, without the thresholds expectable if skills acquired at a particular level were involved (Cleland, 1990; Cleland and Kaufman, 1998; Jejeebhoy, 1995). These analyses, like others reviewing the literature (Diamond et al., 1999), have nevertheless called for more empirical evidence on the links between female schooling and demographic outcomes.

Three recent studies have provided evidence of a literacy link based on direct assessment of women's literacy skills. Glewwe (1997, 1999) analyzed data from 1495 Moroccan mothers with children aged 5 or younger who participated in the 1990-1991 Enquete National sur le Niveau de Vie des Menages, a national survey of 3323 households, based on the World Bank's Living Standards Measurement Study (LSMS). The mothers were given a battery of tests covering health knowledge, general knowledge (actually a functional literacy test), numeracy and literacy in French and Arabic. The child's health was assessed through height-for-age (an inverse measure of "stunting" or chronic malnutrition). Mother's schooling predicted child health with other socioeconomic factors controlled, and so did functional literacy skills in Arabic. Glewwe (1997) also found that maternal health knowledge was the best predictor of child health. He concluded, "education improves child health primarily by increasing health knowledge," even though Moroccan schools do not teach such knowledge directly; instead, children acquire literacy and numeracy skills in school, which they then use to obtain health knowledge outside of school (Glewwe, 1997, p. 151).

In a South African study, Thomas (1999) analyzed data from 778 black South African women aged 15-49 who participated in the 1993 survey of the Project for Statistics for Living Standards and Development (PSLD) of South Africa, which covered 9,000 households. These women were given a Literacy Assessment Module (LAM) testing three basic skills: reading comprehension, listening comprehension, practical mathematics and computational skill. Regression analysis showed schooling to be a strong predictor of children ever born (CEB), controlling for age and rural-urban residence: Each additional year of school attendance is associated with 0.12 fewer children. Reading comprehension was an apparent vehicle of this influence: The average woman who answered all six comprehension questions correctly had nearly half a child less than a woman who failed to answer any of the questions correctly, and controlling for income did not alter this finding. Thomas concludes, "Women with better comprehension skills may be better able to access and assimilate information in the community. They may thus be likely to be better informed than their peers and 
therefore better able to use community services effectively," (1999, p. 172).

The third study, an analysis of Guatemalan data by Khandke et al. (1999), involved 266 children and their mothers who were participants in a longitudinal supplementation study conducted by the Institute of Nutrition in Central America and Panama (INCAP) from 1969 to 1977 in four Spanish-speaking villages of rural eastern Guatemala. The children were monitored weekly for respiratory illness during the first four years of life; mothers took a literacy test based on local materials (Gorman and Pollitt, 1997). Maternal schooling ranged from $0-6$ years, with a mean of 1.34 and a standard deviation of 1.39. Khandke, Pollitt and Gorman found that the children of mothers with 4-6 years of schooling had less respiratory illness than mothers with $1-3$ years of schooling (with socioeconomic variables controlled) and that a mother's literacy score was a significant inverse predictor of her child's respiratory illness at four years of age, in a regression model that controlled for socioeconomic status and maternal school attainment.

Thus evidence from Morocco, South Africa and Guatemala has shown that when literacy testing was added to large-scale surveys or surveillance studies, the results suggest a pathway from women's schooling to demographic outcomes through literacy and health information. These results encourage continued exploration of how literacy might mediate the relationship between school experience and women's reproductive and health behavior.

\subsection{The conceptualization of literacy}

What is literacy and how is it measured? During the last 20 years, there have been major advances in the scientific understanding of literacy, representing contributions from history, anthropology, psychology, linguistics and educational research (Wagner et al., 1999). The multidisciplinary literature of theory and research encompasses diverse viewpoints and methodological approaches. There is, nonetheless, an apparent consensus on some findings and principles directly relevant to population studies:
First, although literacy always has something to do with the use of writing and written texts, its definition varies across social settings and historical conditions. Persons deemed literate in one culture or setting would not necessarily be considered literate elsewhere. Changes in religion, government, technology and the labor market have resulted in changing definitions of literacy (Wagner, 1995, 2000).

Second, literacy as an individual characteristic is not a unitary phenomenon but is more accurately conceptualized in terms of the diverse literacy practices (i.e., reading newspapers, writing letters, calculating monetary change for a customer) in which individuals in a population can acquire proficiency. The calculation of literacy rates that bifurcate each population into literates and illiterates is neither valid nor informative (Wagner, 1995). It tells us little about the distribution of competence or proficiency in the socially valued literacy practices of a community. Nations continue to record figures on rates of literacy and illiteracy, and United Nations agencies continue to assemble, publish and use them, notwithstanding the fact that literacy researchers have long since abandoned the distinction on which they are based as being crude, simplistic and misleading.

Third, the learning of basic academic literacy in school is a continuous process of development with a strong cognitive component. It begins with mastery of the elementary skills required to sound out and inscribe words and sentences but soon moves on to the comprehension of increasingly complex texts. This process is not complete after four or five years of primary school; children and adolescents continue toward higher stages of ability in reading and writing up to and during postsecondary schooling (Chall, 1996). It was once thought that children always became literate in four or five years of schooling (if the schools were reasonably effective and the children of average ability). The convention established in national censuses and accepted by the UNESCO Statistical Yearbook divides the population over 15 years of age into literates and illiterates by whether or not they have completed five or more years of school. This criterion, in addition to underestimating the literacy practices that might have been mastered 
by those who did not stay in school for five years, lumps together as literates those who can comprehend only the simplest of texts with those whose mastery has been extended to complex and sophisticated materials and who can write as well as read in a cognitively advanced way. Furthermore, the reading and writing of advanced texts in Western-type schools involves a number of other cognitive and communication processes such as the acquisition of metalinguistic awareness, metacognition and a context-reduced (academic) speech register (Snow et al., 1998). The resulting proficiencies, all of them properly conceptualized as literacy skills, can continue to improve with additional years of schooling in secondary school and beyond.

This last point is particularly relevant to the argument that literacy is not a plausible link between female schooling and child survival because differentials in child mortality by maternal schooling show no thresholds; they are found at the upper as well as the lower end of the range of schooling (Cleland, 1990; Jejeebhoy, 1995). The argument is based on the assumption that school literacy does exhibit sharp thresholds like the one posited by the UNESCO criterion, that is, that those with less than five years of school lack the ability, and those with five years or more have it. This assumption is inconsistent with the contemporary view of literacy researchers that proficiencies in academic reading and writing skills are continuous variables that show progress long after five years of schooling. If literacy skills are continuous variables that improve throughout the range of women's schooling, then they might be more closely related to schooling and child survival variables than has been assumed.

In recent decades, national literacy surveys using direct assessment methods have been carried out in several countries. These include the Young Adult Literacy Survey (Kirsch and Jungeblut, 1986) and National Adult Literacy Survey (Kirsch et al., 1993) in the United States, the National Literacy Skill Assessment in Canada (Statistics Canada, 1990), and the first International Adult Literacy Survey (OECD/Statistics Canada, 1995). The latter is particularly relevant here.
In the International Adult Literacy Survey, seven countries (Canada, Germany, Netherlands, Poland, Sweden, Switzerland and the United States) were covered. A probability sample of some 2000-4000 adults aged 16-65 was drawn from each national population and tested at home. Proficiency was defined in three literacy contexts selected to represent skills required for economic, social and political participation in a modern industrial society: prose literacy, document literacy and quantitative literacy. Prose literacy refers to the ability to understand and use information contained in textual material such as newspapers, magazines and brochures. Document literacy refers to the knowledge and skills needed to process information contained in tables, schedules, charts, graphs, maps and forms. Quantitative literacy means using arithmetic operations to perform tasks based on texts containing numbers. The investigators developed psychometric scales to measure proficiency in these contexts, and then examined the distributions of test scores across nations and by gender, level of schooling, occupation and income within each country. They found that literacy skills vary significantly across and within the nations covered by the survey, and that literacy as measured in the survey is not synonymous with educational attainment. For example, in Poland $2.3 \%$ of those with complete secondary education but no further schooling scored at the highest level on the prose scale, whereas the equivalent figure in Germany and the United States was $14 \%$ and in Sweden $31.1 \%$. They also found that many respondents when asked to assess their own literacy skills tended to make favorable estimations. Over $80 \%$ in every country rated their reading in daily life as good or excellent, and many who scored at the lowest level on reading tests reported their reading skill to be excellent for their jobs. One conclusion from the survey is of direct relevance to demographic and health surveys: "Education is, by itself, not a satisfactory or simple proxy for literacy," (OECD/Statistics Canada, 1989, p. 77).

The studies of Morocco (Glewwe, 1997, 1999), South Africa (Thomas, 1999), and Guatemala (Khandke et al., 1999; Gorman and Pollitt, 1997) in which direct literacy assessment was used and 
related to demographic variables have been described earlier in this article. Their promising results combined with the other literacy surveys reviewed in this section show that literacy is ready to assume a more important role in population studies, one in which it is neither taken for granted nor dismissed but studied empirically in relation to the processes of reproductive change. Literacy research has not quite achieved the consensus on methods that had been achieved in nutrition and child health research by 1983 (Moseley and Chen, 1984), and perhaps it never will, since literacy skills (unlike anthropometrics) will always be defined in relation to particular social conditions. It is now clear, however, that literacy can be validly and profitably measured with various instruments in large-scale demographic and health surveys.

\subsection{A program of research on literacy and maternal health behavior}

In the Project on Maternal Schooling at the Harvard Graduate School of Education we have been investigating the links between women's schooling and reproductive change in Mexico, Nepal, Zambia and Venezuela. Our field studies of urban and rural sites have combined ethnographic fieldwork with community-level surveys and literacy testing, within populations in which available demographic evidence has shown associations between women's schooling and changing levels of child survival and fertility. Six sites have been studied, including rural and urban sites in Mexico and Nepal and urban sites in Zambia and Venezuela (LeVine et al., 1991, 1994; Joshi, 1994; Stuebing, 1997; Dexter et al., 1998; LeVine et al., 2001, LeVine et al., in press). By replicating the study in maximally diverse sites, we hoped to identify similarities and differences in the processes by which schooling affects reproductive and health behavior and to provide tentative estimates of causal pathways that could be investigated more definitively in large-scale, longitudinal and quasi-experimental studies.

We have recently reviewed the educational research literature on schools and classrooms from a comparative point of view and proposed a framework of four plausible pathways (aspirations, skills, identity/empowerment, and models of learning and teaching) through which the schooling of women in developing countries might affect demographic change (LeVine et al., 2001). Although we believe that all four are probably implicated in the complex processes of school influence on maternal behavior, we have increasingly focused our research on the skill pathway, particularly proficiency in academic language and literacy skills acquired in school, as described below and illustrated by Fig. 1 .

This change in focus resulted from our studies in rural Mexico, rural Nepal and urban Zambia in which we assessed mothers' reading comprehension and oral academic language proficiency. In these studies we found that school attainment during childhood and adolescence was strongly and robustly related to adult literacy skills and to comprehension of written and oral health messages (LeVine et al., 1994; Joshi, 1994; Dexter et al., 1998; Stuebing, 1997). These findings called for a closer examination of literacy as a link between school experience and maternal behavior, which we conducted in Venezuela and Nepal (LeVine et al., 2001; LeVine et al., 2004 in press). This article reports findings from the Venezuela study of 1992-1995.

\subsection{Academic language and literacy proficiency}

The focus of the theoretical model examined in this article is the role of academic language and literacy skills as a mediator between maternal schooling and health-related communication skills. We define academic literacy proficiency as the mastery of reading and comprehending written text as well as the ability to produce increasingly complex written texts. We use the term academic language proficiency to refer to the mastery of discourse skills emphasized in school classrooms and based on the discourse mode of written text. Similar to written text, yet in contrast with everyday conversation, this mode of speaking assumes less shared context, involves the frequent use of abstract nouns, and explicates particulars that are taken for granted among familiar conversational partners. This type 
1.MATERNAL SCHOOLING:

Years of attendance during

childhood and adolescence

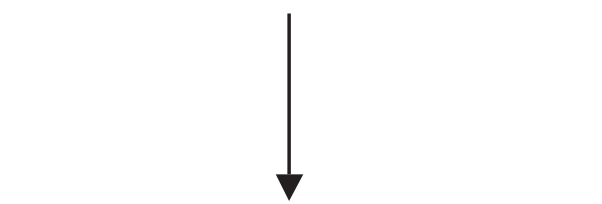

2. LITERACY AND LANGUAGE

SKILLS (in adulthood):

Reading comprehension

Academic language

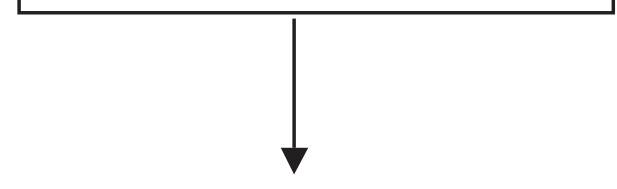

3. HEALTH-RELATED SKILLS:

Understanding health messages

Interacting with health practitioners

\section{UTILIZATION OF SERVICES:}

Prenatal care

Immunization

Contraceptive use

Domestic health practices

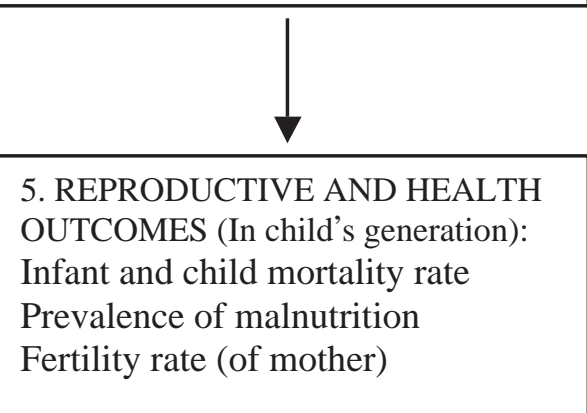

of language use is referred to by Snow (1990) as "decontextualized language ability," by Cummins (1984) as "context-reduced," and Wells (1999) calls it "the synoptic mode of speaking and construing experience". Valdes and GeoffrionVinci (1998) have argued that it constitutes an academic "register" or an institutionalized situation-specific use of language with distinctive linguistic features.

Academic language and literacy skills are used extensively in society including healthrelated institutions such as family planning clinics and hospitals. We hypothesize that women with greater academic literacy skills will have an easier time comprehending printed materials such as instructions on medicine labels or pamphlets about specific illnesses than women with less academic literacy skills or formal schooling. In addition, we propose that the academic register, with its features of formality, impersonality, and abstractness, is the official oral language of such bureaucracies, and proficiency in using the academic register is advantageous in oral communication with health practitioners. For example, it helps in understanding public health messages in the media and medical instructions in the clinic, and in providing a coherent account of symptoms and their emergence to a doctor or nurse. Thus, our theoretical model rests on the hypothesis that girls who attend school longer have more experience with academic language and more training in academic literacy skills than girls with less schooling or no formal schooling at all. Through their school experiences these girls receive practice using academic language and literacy skills in ways that approximate the use of the skills in other social institutions. The more schooling and practice a child gets, the more proficient she is expected to be. We propose that this proficiency in academic language and literacy skills is therefore a mediator between amount of formal schooling and mothers' health-related communication skills and behaviors.

Fig. 1. Hypothetical influences of maternal literacy on health and child development. 


\subsection{The Venezuelan context between 1992 and 1995}

Venezuela is a major oil-producing country of 23 million people with a culture derived from their Caribbean, European (predominantly Spanish) and Native American backgrounds. Ninety-seven percent of its inhabitants live in cities (OCEI, 1998). Caracas, with a population of three million, is the largest city in Venezuela, its capital and center of commerce. Venezuela is one of the oldest and, up until 1992, was one of the most stable democracies in the region.

The decrease in oil prices in the early 1980 s together with the political instability ${ }^{2}$ in the 1990s precipitated an economic crisis in Venezuela from which it has yet to recover. This situation has had devastating social consequences, drastically reducing the standard of living of the great majority of households. During the time of our study 78-80 percent of the population (circa 15.6 million) were living below the poverty line; $2,800,000$ of these Venezuelans were 18 or younger (OCEI, 1998). Families that had been living in 'relative poverty' (defined as a family of 5 or 6 that lives on a monthly income of approx. US\$ 530) slipped into conditions of 'extreme poverty' (defined as a family of 5 or 6 that lives on a monthly income of approx. US\$ 400) or worse (Fundacredesa, 2000). The political and economic crises during the period leading up to and including the years of our study affected the lives of families in La Silsa, through impacts on family planning, child health, and education, each of which is discussed here briefly.

\footnotetext{
${ }^{2}$ At the time of our study Venezuela was experiencing great political turmoil. After two attempted military coups during 1992, the president, Carlos Andres Perez, was forced to step down and tried on corruption charges. The interim president was an eighty-year-old historian who, although widely respected, was not able to provide the country with a badly needed sense of stability. As expected, this political situation seriously affected the economy of the country, which in turn intensified the hardship of a large proportion of the Venezuelan population.
}

\subsection{Family planning}

In the 1960s and 1970s family planning was not a major policy concern for the Venezuelan government. Oil revenues were high, and economic and social growth was welcomed. Indeed, in the 1960s the mean number of births per woman was 6.7 (Nuñez, 1993). So, while birthrates in most Latin American and Caribbean countries were decreasing significantly, partly as a result of governments' family planning programs, this was not the case in Venezuela, according to UNESCO's 1993 Report. Although birthrates have decreased by almost half in the last 30 years, they still remain among the highest in the region (mean number of births per woman in Venezuela in 1993 was 3.4) (Nuñez, 1993).

Following international recommendations to become more cost-effective in the 1980s, the Health Ministry was restructured and family planning became part of a larger program of integrated maternal services. In practice, however, the funds specifically designated for the family planning program were eliminated from the budget, which resulted in the loss of trained personnel and materials, and, with it, the capacity to provide free contraceptive services to low income women (Garip-Bertuol, 1993). In 1989, due to even more drastic budgetary cuts, the Health Ministry stopped buying contraceptives. During the time of our study (1992-1995) low income women had to rely mostly on the social conscience and good will of doctors and health care workers at public hospitals or private clinics to obtain birth control pills (that were either donated or given to hospitals at lower costs by private institutions), to have IUDs inserted or to get a tubal ligation. If they could not afford even those costs, there was nothing else they could do.

Not having effective family planning policies proved costly for the country, particularly in the number of pregnancies among adolescent girls, for whom there were no preventive programs at the time. In 1991, 20 percent of all live births were to women aged 19 or younger, the large majority of who were not in stable unions (Garip-Bertuol, 1993). Thus, the decrease in the number of births over the last fifty years in Venezuela is not the 
result of the government's family planning policy, but is more likely the result of other factors such as the increase in school attainment rates, improved literacy skills (particularly among girls), a decrease in child mortality rates, and growing urban development, though these factors have so far not been systematically investigated (Nuñez, 1993).

\subsection{Child health}

The economic crisis seriously affected the nutritional intake of the population. Malnutrition in the poorest sectors was widespread among people of all ages, who largely subsisted on corn flour, pasta and sardines. Children, however, were the most adversely affected. Studies at the time indicated that rates of child malnutrition had tripled. Chronic malnutrition among children, which used to be no higher than ten percent, was reported to have increased to thirty percent in some states (Davies, 1995). Health workers also reported that increasing numbers of full term infants were born at low birth weight (under $2500 \mathrm{~g}$ ), indicating that their mothers were suffering from malnutrition (El Universal, 1993). UNICEF's 1995 Report on Venezuela revealed that the proportion of low birth weight babies increased from $9.6 \%$ in 1989 to $12.1 \%$ in 1993 . The rate of malnutrition among children below the age of two nationwide was around 12.4 percent, according to the 1995 figures provided by SISVAN (Sistema de Vigilancia Alimentaria y Nutricional), from the National Nutrition Institute (Davies, 1995).

Studies carried out by Fundacredesa indicated that chronic malnutrition among children had already had serious effects on growth patterns (Méndez Castellanos, 1996). In 1993 these studies revealed that only 20 percent of Venezuelan children attained standard measurements for weight and height for children in developed countries. Children living in conditions of 'extreme poverty' were, on average, $7 \mathrm{~cm}$ shorter than children in the higher socioeconomic groups. This difference had been increasing over the years. It had been $4 \mathrm{~cm}$ and by 1993 had almost doubled (El Universal, 1993). As the researchers pointed out, this seemingly small difference in height among children translates into large differences in terms of educational attainment, salary, housing, and life expectancy once they reach adulthood (Risk, 1993).

The national infant mortality rate was 25.1 per 1000 live births, but in poor urban areas the rates were four times higher (OCEI, 1998). The most common causes of infant death were gastrointestinal and acute respiratory infections, preventable illnesses. As Roland Evans, the Dean of the Department of Public Health and Preventive Medicine of the Universidad Central de Venezuela, pointed out, Venezuela's mortality rates were characteristic of developed countries, but its morbidity rates corresponded to low-income Third World countries (El Universal, 1993). According to Evans, poverty is the leading cause of child illness.

\subsection{The educational system}

During the period of our study, the Venezuelan educational system was in a state of deterioration. A 1988 study that tested the reading comprehension of children in fourth and ninth grade in 32 countries put Venezuela in the 29th place, better only than Nigeria, Zimbabwe and Botswana (the research of the Venezuelan children was conducted by Armando Morles from the Universidad Pedagógica Libertador, UPEL) (Estacio, 1993). At the adult level, 1990 estimates from the "Colegio de Economistas" suggested that 47 percent of a work force of 7.4 million people had incomplete primary education or no formal schooling. Furthermore, half of those who had been to school, had forgotten the skills they acquired and were functionally illiterate. Functional illiteracy was found even among teachers. A 1994 study by the Universidad Central de Venezuela's Education School found that 22 percent of a sample of 176 teachers in their teacher-training programs were functional illiterates (Nuñez, 1993). It was therefore not surprising that the " 1994 World Competitiveness Report" ranked Venezuela 40th out of 41 countries in the quality of education category, based on available statistics and on the World Economic Forum's executive opinion poll (Anderson, 1995). 
In spite of the poor quality of the Venezuelan educational system, figures suggest that women's schooling can make a difference in health and reproductive behavior. As in other developing countries, the number of children ever born varied considerably with level of schooling attained. For example, 1987 figures for the Federal District (that includes the capital Caracas where our sample was chosen) show that women with no schooling, on average, had three more children $(\mathrm{TFR}=5.79)$ than women who had some post-secondary education (TFR $=2.65)$. Women's education appeared to have a similar impact on child health: Federal District figures indicated that the infant mortality rate (IMR) for unschooled women was 43 per 1000 live births, whereas that of women with postsecondary schooling was 13 , less than one third (Méndez-Castellano, 1996). But knowing that education can make a difference, even in poor quality schools, is not enough. Research is needed to determine what specifically accounts for these changes and to what extent schooling is responsible for the outcome controlling for other aspects of socio-economic status (SES).

\subsection{The research site: Barrio La Silsa}

Like many barrios in Caracas, La Silsa is the result of the massive migration from the rural areas that began at the end of the 1950s, at the time of the first democratic government in Venezuela. According to its oldest inhabitants, the barrio was founded in 1960. At the time of our study its population of approximately 30,000 people included a range of socio-economic levels from lower middle class to 'extreme' poverty. The settlement patterns within the barrio, located on a mountainside, roughly reflected these differences. At the bottom of the mountain were the better-off families (most original settlers) with a relatively high standard of living, in terms of housing conditions and access to services, whereas the poorest and most recent arrivals - both from rural areas in Venezuela as well as illegal immigrants from neighboring countries-lived further up the mountain.

Although La Silsa is one of the oldest barrios in Caracas, public services were a concern for most of its inhabitants. Water, electricity and trash collection were less of a problem for the better-off families at the entrance to the community. However, educational and health services were mentioned as serious problems by all. There were only two preschools within the barrio one run by the church and the other by the government, but only one educational facility, also run by the church, to accommodate the large primary and secondary school-age population. Most children had to attend public schools outside their community.

There was only one small clinic within La Silsa run by a Catholic priest with government-appointed doctors and nurses. The community and the medical personnel at the clinic had, unfortunately, a very poor relationship. The absenteeism of doctors and nurses was very high, often resulting in mothers having to wait for months for a medical appointment, or having to go to more distant public hospitals. Furthermore, because this clinic was run by the Catholic church it did not include family planning among its services, so women had to go outside the community for these services.

The lack of adequate police protection within the community was mentioned as the more serious problem for residents. Drug selling and consumption was rampant, making La Silsa an extremely dangerous place, particularly after $6 \mathrm{p} . \mathrm{m}$. and at weekends. Mothers in our study reported that they never ventured out of the house after this hour, often not even when there was an emergency such as a very ill child. The only community-wide structure that existed in the barrio was a recently established "Junta de Vecinos", a grassroots organization that tried to maintain law and order and solve neighborhood problems. In our interviews most mothers expressed the desire to move away from La Silsa to be able to raise their children in safer surroundings.

To provide a general picture of the mothers living in La Silsa we present selected demographic characteristics of our sample of 161 mothers of children under five in Table 1 . The average mother in our sample was, at the time of the survey, 26.6 years old and had been living in La Silsa for approximately 17 years, having usually lived in the interior of the country prior to moving to Caracas 
Table 1

Demographic characteristics of women in La Silsa $(n=161)$

\begin{tabular}{lll}
\hline & Mean (SD) & Range \\
\hline Women's age & $26.6(6.9)$ & $14-46$ \\
Age at birth of target child & $20.6(4.8)$ & $14-45$ \\
Years living in La Silsa & $16.9(9.6)$ & $0-36$ \\
Woman's schooling (years) & $7.4(3.0)$ & $0-14$ \\
Husband's schooling (years) & $7.8(2.6)$ & $0-14$ \\
Children living (number) & $2.4(1.5)$ & $1-9$ \\
Desired number of children & $2.7(1.3)$ & $1-9$ \\
Women's mother's schooling (years) & $4.1(3.1)$ & $0-13$ \\
Women's father's schooling (years) & $5.1(3.1)$ & $0-11$
\end{tabular}

${ }^{\text {a } D a t a}$ on father's schooling were only available for the 98 women who were not abandoned by their fathers in early childhood.

to settle down in the barrio. As a child she attended school for a little more than 7 years (level equivalent to last year of primary school or first year of high school in the Venezuelan school system), indicating that she attended school almost twice as long as her mother did (4.1 years). She is likely to be living with a partner (few low income women in Venezuela are in legal unions) who attained a somewhat higher level of schooling than she did (7.8 years). She gave birth to the target child in our study (often her first born) at or before the age of 20 (not necessarily a child from her present partner), and currently has about 2-3 children, which corresponded to Venezuela's current mean birthrate (3.4).

Maternal schooling is related to fertility and health behaviors in this sample of mothers from La Silsa, as it is for the country as a whole. The partial correlation of maternal schooling with number of living children, controlling for maternal age, is $-0.31(p<0.0001)$. Controlling for maternal age, childhood SES and current SES the partial correlation is $-0.29(p<0.001)$. Therefore, taking women's age and SES into account, women with more schooling have fewer children than women with less schooling. The partial correlation between schooling and earliness of prenatal care during the mothers' last pregnancy is 0.26 $(p<0.001)$ controlling for age and SES, indicating that women with more schooling started prenatal care earlier than women with less schooling. Thus, within this sample of mothers from La Silsa there are the relationships between schooling and reproductive outcomes necessary for a study of pathways through which schooling might influence health-related communication skills.

Our specific research questions in this study are as follows: (1) Do mothers retain the language and literacy skills they learned in school? (2) Do these academic language and literacy skills have an independent effect on health-related communication skills such as their ability to comprehend health messages and their ability to provide a coherent narrative to a health practitioner?

\section{Methods}

All 161 mothers were interviewed and their literacy and health-related communication skills were assessed. The maternal interview covered the woman's socioeconomic and educational background, the schooling of her parents, husband and siblings, the current socioeconomic conditions in which she was raising her children, her reproductive and health behavior, her knowledge of child development, and her attitudes toward her own children. The assessment of maternal literacy skills included reading comprehension and academic oral language proficiency (noun definitions). The assessment of health-related communication skills included comprehension of health messages in both print and broadcast media and the ability to provide a health narrative in an interview situation resembling that used in clinics. Description of the literacy and health-related communication assessment tasks follow.

\subsection{Reading comprehension}

This task consisted of six health-related texts (topics included diarrhea, burns, otitis, measles) graded by difficulty of comprehension according to school grade levels 1, 3, 5, 7, 9 and 11. First, women were asked to read the grade level 1 text aloud so that the investigator could determine if the woman could only decode words or if she could actually read based on the type and number of errors she made. Then, each woman was asked 


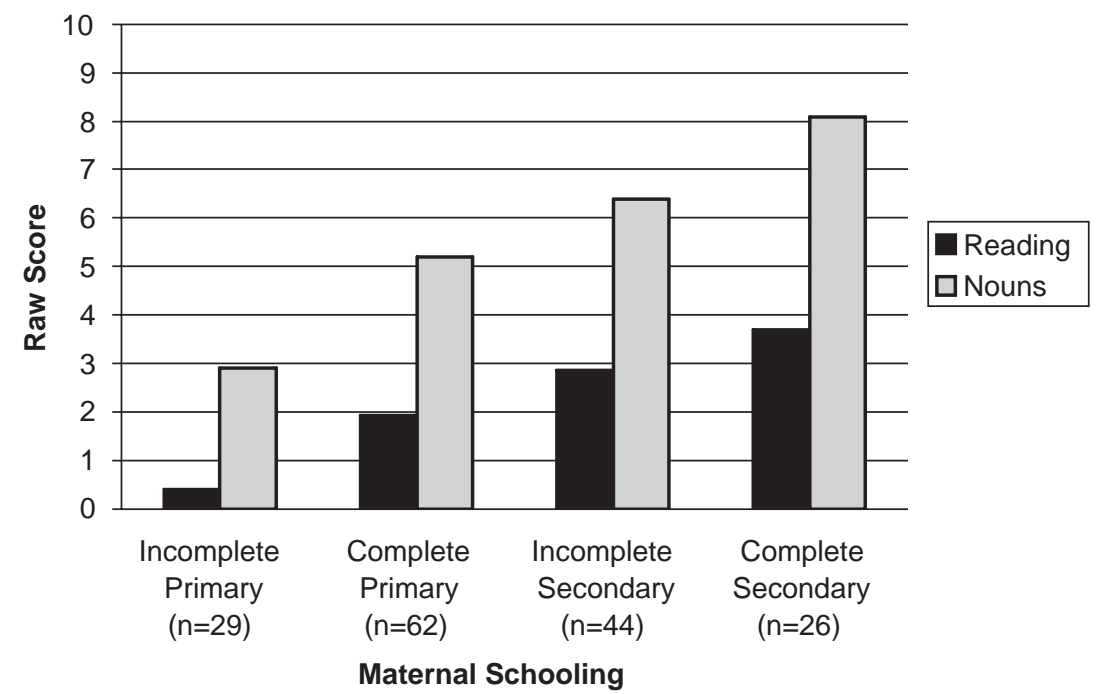

Fig. 2. Mean maternal reading comprehension and noun definition scores by level of schooling $(n=161)$.

Notes:

Schooling levels: Incomplete Primary $=0-5$ years, Complete Primary $=6-7$ years, Incomplete Secondary $=8-10$ years, and Complete Secondary $=11+$ years.

Reading: Possible scores ranged from $0-5$.

Nouns: Possible scores ranged from $0-10$.

to read the texts in order of difficulty and asked questions about their contents. Her score was the grade level at which she was able to recall 50 percent of the idea units (units of information determined by the investigators) contained in each text, aided by questions if mothers did not recall idea units on their own. The scores were converted into a continuous scale of $0-5$. Thus the mean scores for reading shown on Fig. 2 are based on this scale and do not represent the actual grade or class levels in school of the mothers' performance. The overall sample mean was $2.19(\mathrm{SD}=1.7)$, which is equivalent to an average reading level of grade 5 .

\subsection{Noun definitions}

This task was based on the method and rationale of Snow (1990) and had been used in our own previous field studies. Each mother was asked to define ten nouns for common objects, such as "knife," "thief," and "dog," with the question, "What is a _-_?" Their responses were scored for the presence or absence of superordinate category membership ("a dog is an animal..."), and the scores shown on Fig. 2 are the mean number of objects for which a superordinate term like "animal" was given; this is an indicator of what Snow (1990) calls decontextualized language use. Decontextualization in this sense refers to the ability to communicate meaning through words alone to someone who does not share the same context in background knowledge or current experience; it does not mean that any verbal communication is entirely free of context. The ability to use the less contextual, more abstract and more explicit language taught in schools to define a noun is our measure of academic language proficiency. The average number of correct definitions provided was 5.57 $(\mathrm{SD}=3.1)$ out of ten.

\subsection{Comprehension of radio health messages}

All mothers were played a tape recording of two health messages (about AIDS, family planning) to examine their oral comprehension skills. The content of each of these messages was divided 
into idea units. Mothers were told to listen carefully to each message and to tell the examiner everything they could remember. Responses were coded for idea units mentioned, the total number of which constituted a score. The maximum possible score was 19, with 8 idea units for the AIDS messages, and 11 for family planning. The mean total score was $6.89(\mathrm{SD}=3.4)$, with a range from 0 to 16 . For the additional analyses presented here scores on AIDS and family planning messages were standardized and summed to create one composite variable for comprehension of radio messages.

\subsection{Comprehension of printed health messages}

All mothers, except those with incomplete primary (less than 5 years of schooling) were presented with two additional radio messages but in written form about AIDS and family planning. Mothers were given these print messages one-byone and asked to take as much time as they needed to read them. Then they were asked to tell the examiner everything they could remember about each message they had read. Their responses were coded for idea units. The maximum possible total score was 16, with 8 idea units for both AIDS and family planning. The mean total score was 6.03 $(\mathrm{SD}=2.68)$, with a range from one to 13 . For the additional analyses presented here, scores on AIDS and family planning messages were standardized and summed to create one composite variable for comprehension of print messages.

\subsection{Health narratives}

This task was designed to simulate the response to questioning in a health clinic. Mothers were asked to recount a health crisis involving their child participating in our study. Interviewers were instructed to prompt the mothers with general questions (e.g., and then what happened?). If a mother seemed to provide too short an account or was missing important information (what steps she took, what type of medication she used, if the child recovered, etc.), the interviewers asked more specific questions (e.g. did you take him to the doctor?). A maximum of 10 specific questions was allowed. Narratives were coded for organizationhow well a health practitioner would be able to follow and understand the narrative based on how the mother structured her account. In addition, as mothers chose to talk about different illnesses their children had experienced, the severity of the health problem in terms of how close to death the child had been was considered. Narrative organization and illness severity were rated on 5-point scales, with higher numbers representing more organized narratives and more severe illnesses. A pediatrician judged the severity of the child illnesses. Narrative organization was coded by two Native Spanish speakers who had reached acceptable levels of reliability on the measure through training. The average narrative organization score was 3.45 $(\mathrm{SD}=1.2)$ and the average severity of the illness rating was $2.52(\mathrm{SD}=1.2)$. Illness severity and narrative organization were positively associated $(r=0.20, p<0.05)$ with mothers providing more organized narratives about more severe illnesses. Thus, in further analyses of predictors of narrative organization, illness severity will be controlled for.

\section{Results}

To answer our first research question concerning whether Venezuelan mothers retain language and literacy skills learned in school we show the associations between schooling and various maternal language and literacy skills. We demonstrate that these associations hold when controlling for socioeconomic factors (see also LeVine et al., 2001 for a comparative discussion of these findings). To determine whether these skills have an independent effect on health-related communication skills as posited in the theoretical model displayed in Fig. 1, we present multiple regression analyses looking at the effect of literacy on various healthrelated tasks controlling for schooling and socioeconomic characteristics.

\subsection{Retention of language and literacy skills acquired in school}

Fig. 2 shows the relationship between maternal language and literacy skills and schooling. As can 
be seen scores on the academic oral language (noun definition) and reading comprehension tasks are higher for mothers with higher schooling levels. For example, the average number of formal noun definitions provided by women who had not completed primary school was 2.91 out of a possible score of 10 , while women who had completed secondary schooling averaged 8.08 formal definitions. These differences in average scores on the literacy assessments between groups indicate that small increases in schooling between primary and secondary school are associated with gradual improvements in academic language and reading comprehension skills.

Table 2 shows the estimated simple correlations between women's schooling as a continuous variable and academic literacy skills (noun definitions and reading comprehension), health media and narrative skills, and socioeconomic controls. Academic literacy skills are highly correlated with maternal schooling, with correlations ranging from $r=0.54(p<0.001)$ for noun definitions to $r=0.58(p<0.001)$ for reading comprehension. Maternal schooling is moderately correlated with women's abilities to comprehend oral health messages $(r=0.21, p<0.01)$ and to provide an organized oral narrative of her child's illness $(r=0.36, p<0.001)$. Maternal schooling is only

Table 2

Simple correlations (Pearson's $r$ ) of mother's schooling with academic literacy skills, health-related communication skills and socioeconomic variables $(n=161)$

\begin{tabular}{ll}
\hline & Maternal schooling \\
\hline $\begin{array}{l}\text { 1. Academic skills } \\
\text { a. Reading comprehension }\end{array}$ & $0.58^{* * *}$ \\
b. Noun definitions & $0.54^{* * *}$ \\
& \\
2. Health-related communication skills & \\
a. Listening comprehension & $0.21^{* *}$ \\
b. Print comprehension $(n=132)$ & $0.15 \sim$ \\
c. Narrative organization & $0.36^{* * *}$ \\
& \\
3. Socioeconomic variables & \\
a. Age & $-0.41^{* * *}$ \\
b. Current SES & $0.31^{* * *}$ \\
c. Childhood SES & $0.39^{* * *}$ \\
\hline
\end{tabular}

$\sim p<0.10 ; \quad{ }^{* *} p<0.01 ; \quad{ }^{* * *} p<0.001$.
Table 3

Regression models predicting literacy skills (formal noun definitions and reading comprehension level) on the basis of maternal schooling controlling for socioeconomic status (SES) and maternal age $(n=161)$

\begin{tabular}{lll}
\hline Predictors & \multicolumn{2}{l}{$\beta$-coefficient $($ Standard error) } \\
\cline { 2 - 3 } & $\begin{array}{l}\text { Academic } \\
\text { language } \\
\text { (Noun } \\
\text { definitions) }\end{array}$ & $\begin{array}{l}\text { Reading } \\
\text { comprehension } \\
\text { level }\end{array}$ \\
\hline Intercept & -0.43 & 0.34 \\
Maternal & $(1.20)$ & $(0.65)$ \\
Schooling & $0.54^{* * *}$ & $0.30^{* * *}$ \\
Childhood SES & $(0.08)$ & $(0.04)$ \\
& $0.14^{*}$ & 0.02 \\
Adult SES & $(0.07)$ & $(0.04)$ \\
& -0.25 & 0.09 \\
Age & $(0.21)$ & $(0.11)$ \\
$R^{2}$ statistic & 0.06 & -0.02 \\
\hline
\end{tabular}

${ }^{*} p<0.05 ; \quad{ }^{* * *} p<0.001$.

slightly related to women's abilities to comprehend printed messages $(r=0.15, p<0.10)$ due to the exclusion of women with the least amount of education. Table 2 also presents significant correlations between maternal schooling and socioeconomic controls indicating the need for multivariate analyses.

Table 3 presents the results of multiple regression analyses where the two literacy variables are regressed on maternal schooling and socioeconomic controls. Maternal schooling predicts both academic language $(p<0.001)$ and reading comprehension $(p<0.001)$, controlling for socioeconomic factors. Women's childhood SES is also associated with ability on the noun definition task $(p<0.05)$. The $R$-squared statistics indicate that approximately $32 \%$ of the variance in academic language, and $36 \%$ of the variance in reading comprehension is accounted for by maternal schooling and socioeconomic controls. These results provide evidence that the mothers in $\mathrm{La}$ 
Silsa retained academic language and reading comprehension skills learned in school, and that their scores on these literacy tasks can be reliably predicted from their years of schooling, controlling for their age and socioeconomic status. Yet, while schooling is a strong predictor of these literacy skills, it is important to note that it does not tell the whole story. After accounting for schooling and socioeconomic controls, a large amount of variation remains in reading comprehension and academic language skills, suggesting that schooling alone is not an appropriate proxy for literacy skills. Our next step was to examine whether these literacy skills influence women's abilities on health media comprehension and oral narrative skills, controlling for years of formal schooling.

\subsection{Relationship between literacy and health- related communication skills}

To examine the effect of academic literacy on health media and narrative skills we used principal components analysis to construct a literacy composite from the noun definition and reading comprehension variables. These variables were correlated with one another $(r=0.48, p<0.001)$, and the first principal component weighted each variable equally and captured $74 \%$ of the original variance. To examine the independent effects of schooling and literacy we first regressed oral and print comprehension of health media messages and narrative organization on maternal schooling and controls and then, in a final model, we added the

Table 4

Regression models predicting comprehension of auditory (radio) and print health-related messages and health narrative organization on the basis of maternal schooling and socioeconomic controls, with and without literacy skills

\begin{tabular}{|c|c|c|c|c|c|c|}
\hline \multirow[t]{3}{*}{ Predictors } & \multicolumn{6}{|c|}{$\beta$-coefficient (standard error) } \\
\hline & \multicolumn{2}{|c|}{$\begin{array}{l}\text { Auditory } \\
\text { comprehension } \\
(n=161)\end{array}$} & \multicolumn{2}{|c|}{$\begin{array}{l}\text { Print } \\
\text { comprehension } \\
(n=132)\end{array}$} & \multicolumn{2}{|c|}{$\begin{array}{l}\text { Health narrative } \\
\text { organization } \\
(n=157)\end{array}$} \\
\hline & $\begin{array}{l}\text { First } \\
\text { Model } \\
\text { (1) }\end{array}$ & $\begin{array}{l}\text { Final } \\
\text { Model } \\
\text { (2) }\end{array}$ & $\begin{array}{l}\text { First } \\
\text { Model } \\
(3)\end{array}$ & $\begin{array}{l}\text { Final } \\
\text { Model } \\
(4)\end{array}$ & $\begin{array}{l}\text { First } \\
\text { Model } \\
(5)\end{array}$ & $\begin{array}{l}\text { Final } \\
\text { Model } \\
(6)\end{array}$ \\
\hline Intercept & $\begin{array}{l}-0.33 \\
(0.74)\end{array}$ & $\begin{array}{l}0.95 \\
(0.74)\end{array}$ & $\begin{array}{l}0.32 \\
(0.83)\end{array}$ & $\begin{array}{l}0.83 \\
(0.83)\end{array}$ & $\begin{array}{l}1.89^{* * *} \\
(0.55)\end{array}$ & $\begin{array}{l}2.67^{* * *} \\
(0.58)\end{array}$ \\
\hline $\begin{array}{l}\text { Maternal } \\
\text { Schooling }\end{array}$ & $\begin{array}{l}0.13^{*} \\
(0.05)\end{array}$ & $\begin{array}{l}-0.02 \\
(0.05)\end{array}$ & $\begin{array}{l}0.09 \\
(0.06)\end{array}$ & $\begin{array}{l}0.01 \\
(0.06)\end{array}$ & $\begin{array}{l}0.12^{* * *} \\
(0.03)\end{array}$ & $\begin{array}{l}0.05 \\
(0.04)\end{array}$ \\
\hline $\begin{array}{l}\text { Childhood } \\
\text { SES }\end{array}$ & $\begin{array}{l}-0.01 \\
(0.04)\end{array}$ & $\begin{array}{l}-0.03 \\
(0.04)\end{array}$ & $\begin{array}{l}0.03 \\
(0.04)\end{array}$ & $\begin{array}{l}0.02 \\
(0.04)\end{array}$ & $\begin{array}{l}-0.001 \\
(0.03)\end{array}$ & $\begin{array}{l}-0.01 \\
(0.03)\end{array}$ \\
\hline $\begin{array}{l}\text { Current } \\
\text { SES }\end{array}$ & $\begin{array}{l}-0.19 \\
(0.13)\end{array}$ & $\begin{array}{l}-0.19 \\
(0.12)\end{array}$ & $\begin{array}{l}-0.18 \\
(0.12)\end{array}$ & $\begin{array}{l}-0.17 \\
(0.12)\end{array}$ & $\begin{array}{l}0.11 \\
(0.09)\end{array}$ & $\begin{array}{l}0.12 \\
(0.08)\end{array}$ \\
\hline $\begin{array}{l}\text { Maternal } \\
\text { Age }\end{array}$ & $\begin{array}{l}-0.01 \\
(0.02)\end{array}$ & $\begin{array}{l}-0.01 \\
(0.02)\end{array}$ & $\begin{array}{l}-0.03 \\
(0.02)\end{array}$ & $\begin{array}{l}-0.03 \\
(0.02)\end{array}$ & $\begin{array}{l}-0.01 \\
(0.01)\end{array}$ & $\begin{array}{l}-0.01 \\
(0.01)\end{array}$ \\
\hline $\begin{array}{l}\text { Illness } \\
\text { Severity }\end{array}$ & & & & & $\begin{array}{l}0.21^{* *} \\
(0.07)\end{array}$ & $\begin{array}{l}0.17^{*} \\
(0.07)\end{array}$ \\
\hline $\begin{array}{l}\text { Literacy } \\
\text { Composite }\end{array}$ & & $\begin{array}{l}0.61^{* * *} \\
(0.13)\end{array}$ & & $\begin{array}{l}0.36^{* *} \\
(0.01)\end{array}$ & & $\begin{array}{l}0.31^{* * *} \\
(0.09)\end{array}$ \\
\hline$R^{2}$ statistic & 0.065 & 0.187 & 0.075 & 0.124 & 0.182 & 0.241 \\
\hline
\end{tabular}


effect of literacy to determine whether academic literacy skills learned in school explained any additional variance in health-related communication skills, controlling for schooling and socioeconomic factors.

Table 4 shows the results of these regression analyses. In Model 1, maternal schooling is a significant predictor of comprehension of radio health messages, controlling for age and socioeconomic status. These predictors together explain approximately 7.0 percent of the variance in comprehension of auditory radio messages. In the final model (Model 2), in which the literacy composite was added as an additional predictor, the estimated effect of maternal schooling is reduced to non-significance, but the literacy composite shows a significant effect $(p<0.001)$, controlling for age, SES and schooling. In this final model 19 percent of the variance in comprehension of radio messages is explained.

Models 3 and 4 show the results for printed health-related messages. For these analyses we did not include the mothers with incomplete primary education, as they were not given the print comprehension task, as it was too hard for them $(n=29)$. In doing this we reduced not only our sample size, but also the amount of variation in the dependent variable. Had we included these women and imputed a score of 0 on the print comprehension measure, we may have potentially inflated our relationships between schooling and literacy and the print comprehension measure. Thus, we chose the more conservative approach with a resulting sample size of 132. Model 3 shows that, taken together, maternal schooling, age and SES explain approximately 8 percent of the variance in comprehension of print messages. Schooling on its own had a slight $(p<0.10)$ relationship with print comprehension, yet upon the inclusion of the controls this effect was reduced. In the final model (Model 4), however, maternal literacy is a significant predictor of print comprehension $(p<0.01)$, controlling for age, SES, and schooling. And, the magnitude of the schooling effect, albeit non-significant, was reduced upon the inclusion of literacy skills. This final model containing literacy, schooling and controls, explains approximately
$12 \%$ of the variance in comprehension of printed health messages.

Models 5 and 6 in Table 4 show the results of the regressions predicting narrative organization for all 157 mothers who provided narratives of child illnesses. Model 5 shows that controlling for maternal age, SES, and the severity of the illness discussed, maternal schooling has a significant positive effect on the organization of a mothers' narrative about her child's illness $(p<0.001)$. The effect of illness severity was also significant $(p<0.01)$. These variables combined to explain 18 percent of the variance in narrative organization. In Model 6 the academic literacy composite was included and proved a significant predictor of narrative organization $(p<0.001)$, controlling for maternal schooling, illness severity, maternal age and SES. In addition, the inclusion of literacy in Model 6 rendered schooling non-significant, while illness severity remained significant at the $p<0.05$ level. In Model 6, the predictors combined to explain 24 percent of the variance in narrative organizational skill.

In sum, the pattern of findings was consistent across dependent measures. For each healthrelated communication skill in question, when a final model including academic literacy skills was added to a model including schooling and controls, the effect of schooling diminished, the effect of literacy was statistically significant, and the $R$-squared statistic increased. More specifically, for the models predicting comprehension of radio health messages, the inclusion of literacy reduced the parameter estimate for the effect of maternal schooling by 0.15 and increased the $R$ squared statistic by 12 percent. For the models predicting comprehension of printed health messages, the estimated effect of maternal schooling decreased by 0.08 and the $R$-squared statistic increased by 5 percent when literacy was added. Finally, in the models predicting narrative organization, the addition of literacy resulted in a 0.07 reduction in the parameter estimate for the effect of maternal schooling, and a 6 percent increase in the $R$-squared statistic. Taken together, the results of these regression analyses suggest that maternal literacy may be a pathway between years of schooling and a woman's abilities to comprehend 
oral and written health-related media announcements and to provide a health practitioner with a clear understanding of her child's illness.

\section{Conclusions}

This study examined the relationships between schooling, literacy skills, and health-related communication skills in a sample of 161 mothers from the barrio community of La Silsa in Caracas, Venezuela. Results showed a positive relationship between years of schooling and performance on academic literacy tests. Thus, women were found to retain the academic literacy skills they learned in school at a level of proficiency reflecting the amount of schooling they had experienced. Furthermore, women's academic literacy skills were found to predict their abilities to comprehend health-related radio and print messages and to tell an organized narrative about their child's illness above and beyond their years of schooling. Taken together, these findings support the pathways between boxes 1-3 in the theoretical model displayed in Fig. 1 where literacy skills are seen as a mediator between women's schooling and subsequent maternal health-related skills. Further research is needed to test the remainder of the model to determine whether maternal literacy and health skills relate to utilization of services and reproductive and health outcomes.

One limitation to cross-sectional studies of this type is the lack of ability to determine that the relationships found here cannot be explained by selectivity. For example, it is possible that women who went to school longer did so because of a genetically or socially inherited advantage not measured in this study and it was that advantage that lead to greater health-related communication skills. While we are not able to directly address this issue quantitatively, historical evidence can provide some insight here. Anderson (1995) reports that in the early 1990s in Venezuela only one-third of the student population reached the ninth grade. Students dropped out for a number of reasons. Chief among them were economic need and lack of motivation. The younger generation needed to contribute to the family budget, so they often had to leave school. However, many did so quite willingly because the material that is taught is so disconnected from their immediate environment that they failed to see school as the way out of poverty (Venegas, 1993). Girls, meanwhile, had an additional reason for having to leave school early. As the figures we presented earlier indicated, many became pregnant when they were barely starting high school. Our own interviews with mothers also uncovered that the oldest daughters often stayed home to take over childcare and household chores while the mother worked. Thus, we have some evidence from our own sample and others that girls dropped out of school for an array of reasons, many unrelated to ability, wealth or social standing.

The results presented here, coupled with our own previous findings from Nepal, Mexico and Zambia, and the larger surveys in Morocco, South Africa, and Guatemala mentioned above, provide evidence that language and literacy skills may explain the relationship between female schooling and health behavior and reproductive change in diverse parts of the developing world. It is important to note that the magnitude of the results presented here based on the Venezuela sample are not as strong as our results from a recent parallel study in Nepal (LeVine et al., 2004 in press). In the current study, on average, approximately 18 percent of the variation in health-related skills were attributable to academic literacy skills, schooling and controls, yet in our recent study in Nepal $R$ squared statistics averaged approximately 50 percent (LeVine et al., 2004 in press). It is likely that the inclusion of women with no formal schooling in the Nepal sample (approximately 30 percent of the sample) may have inflated the relationships found in that study, whereas the more homogeneous sample in Venezuela led to weaker relationships between education, literacy and health-related communication skills. Differences may also stem from differences in the countries in regard to schooling and social change. At the time of our studies the two countries were at very different stages in the spread of formal schooling, with schooling more prevalent in Venezuela than in Nepal. Furthermore, while 
both countries have made considerable progress in demographic change toward lower mortality and fertility rates over the past forty years, Venezuela has consistently shown a far lower under-five mortality rate than Nepal, indicating that the health skills tapped by the measures in this study may be even more integral to children's survival in Nepal than in Venezuela. Of course, the health situations faced by these Venezuelan women are not at all ideal. Despite these differences in magnitude of effects, the fact that our results in Venezuela parallel our results from Nepal adds merit to our theoretical model as applicable to more and less developed nations.

Our results have important implications for investing in female schooling in developing countries. The finding that there is a linear relationship between years of childhood schooling and scores on an academic literacy test many years later suggests that each additional year of formal schooling adds to the literacy skills retained. These findings are somewhat surprising given the documented deterioration of the educational system in Venezuela during the time of our study, yet they provide some promising results that young women are learning and retaining skills learned in schools, despite the poor quality of education. These results concur with previous results from other developing countries such as Guatemala (Gorman and Pollitt, 1997), yet add to the story by suggesting that literacy skills may mediate the relationship between schooling and health-related skills in adulthood. Thus, encouraging the schooling of girls and making an effort to reduce drop-out rates to keep girls in school longer may result in better health environments for children. Furthermore, the finding that literacy skills may serve as a pathway between years of schooling and health-related knowledge and behaviors suggests that if these literacy skills are learned at a later age and are retained, for example in an adult literacy program, the effect on healthrelated skills and behaviors may be equivalent to the results found here.

This study was limited in that we were not able to definitively exclude the possibility that the relationships found here were due to factors other than the causal influence of schooling and literacy skills. Future studies should collect longitudinal data and include an intensive ethnographic component to investigate why young women did or did not drop out of school. In addition, the sample in the current study was selected to provide a range of variation in schooling and skills within a specific neighborhood and thus was not randomly selected. Therefore, the results found here cannot be generalized to the greater population of Caracas or Venezuela. Despite these limitations, the study had several advantages including its direct assessment of mothers' language and literacy skills, an approach that shows promise for future work.

\section{Acknowledgements}

The Project on Maternal Schooling at the Harvard Graduate School of Education has received support from private foundations, government organizations and international agencies. The analyses of the data from Venezuela reported in this article were funded by the William T Grant Foundation (Grant nos. 96175896 and 1758.01). The Venezuela field study was funded by contracts from the United States Agency for International Development (USAID) to the Academy for Educational Development and from the United Nations Population Fund (UNFPA) to World Education Inc.

The field study in Venezuela was codirected by Beatrice Schnell-Anzola and Ileana RecagnoPuente, with the collaboration of Cristina Otálora and Zulme Lomelli, and the research assistance of Denis Martínez, María Mercedes Mercado, and Yuruany Moreno. The literacy instruments were designed and pre-tested by Beatrice SchnellAnzola and Patricia Velasco. Beatrice SchnellAnzola together with Claudia Ordoñez, Mariana Delgado and Moravia Peralta carried out the coding of the health messages and health narratives. Alina Martínez and Seeta Pai organized the data processing and conducted preliminary analyses. Meredith Rowe conducted the final analyses. We thank Sarah LeVine and Emily Dexter for their helpful comments on earlier versions of this paper. 


\section{References}

Anderson, H.D., 1995. The education plan: more than meets the eye. VenEconomy Monthly, March issue. Caracas, Venezuela.

Caldwell, J.C., 1994. How is greater maternal education translated into lower child mortality?. Health Transition Review 4, 224-229.

Chall, J., 1996. Stages of Reading Development, Revised ed. Harcourt Brace, Forth Worth, TX.

Cleland, J., 1990. Maternal education and child survival: further evidence and explanations. In: Caldwell, J., Findley, S., Caldwell, P., Santow, G., Cosford, W., Braid, J., BroersFreeman, D. (Eds.), What Do we Know About Health Transition? The Cultural, Social and Behavioral Determinants of Health. Australian National University Health Transition Centre, Canberra, pp. 400-419.

Cleland, J., Kaufman, G., 1998. Education, fertility and child survival: unraveling the links. In: Basu, A., Aaby, P. (Eds.), The Methods and Uses of Anthropological Demography. Clarendon Press, Oxford, Eng, pp. 128-152.

Cummins, J., 1984. Wanted: a theoretical frame for relating language proficiency to academic achievement among bilingual students. In: Rivera, C. (Ed.), Language Proficiency and Academic Achievement. Multilingual Matters, Clevedon, Eng, pp. 2-19.

Davies, V., 1995. Déficit nutricional alarmante en seis estados del país [The alarming nutritional deficit in six states of the country]. El Nacional 22-7, C/2.

Dexter, E., LeVine, S.E., Velasco, P., 1998. Maternal schooling and health-related language and literacy skills in rural Mexico. Comparative Education Review 42, 139-162.

Diamond, I., Newby, M., Varle, S., 1999. Female education and fertility: examining the links. In: Bledsoe, C., Casterline, J.B., Johnson-Kuhn, J.A., Haaga, J.G. (Eds.), Critical Perspectives on Schooling and Fertility in the Developing World. National Academy Press, Washington, DC.

universal, El, 1993. Setenta y ocho por ciento de los venezolanos en situación de Pobreza. [Seventy-eight percent of Venezuelans living below the poverty line], 10-11, 2/21.

Estacio, P., 1993. Derrotar el analfabetismo es mejorar la lectura [Beating illiteracy means improving our reading ability]. El Nacional, s/r.

Fundacredesa (Fundación Centro de Estudios sobre Crecimiento y Desarrollo de la Población Venezolana), 2000. Encuesta a 1778 hogares en Caracas en 1999 [A survey of 1778 homes in Caracas in 1999]. El Nacional, 20-10, s/r.

Garip-Bertuol, P., 1993. Multiplying misery: facing the void in family planning and reproductive health. VenEconomy Monthly, September issue. Caracas, Venezuela.

Glewwe, P., 1997. How does schooling of mothers improve child health? Evidence from Morocco. Living Standards Measurement Study Working Paper No 128. The World Bank, Washington, DC.

Glewwe, P., 1999. Why does mother's schooling raise child health in developing countries? Evidence from Morocco. The Journal of Human Resources 34, 124-159.
Gorman, K., Pollitt, E., 1997. The contribution of schooling to literacy in Guatemala. International Review of Education 43, 283-298.

Jain, A., Nag, M., 1986. Importance of female primary education for fertility reduction in India. Economic and Political Weekly 21, 1602-1608.

Jejeebhoy, S., 1995. Women's Education, Autonomy, and Reproductive Behaviour: Experience from Developing Countries. Clarendon Press, Oxford, Eng.

Joshi, A., 1994. Maternal schooling and child health: preliminary analysis of the intervening mechanisms in rural Nepal. Health Transition Review 4, 1-28.

Kasarda, J.D., Billy, J., West, K., 1986. Status Enhancement and Fertility: Reproductive Responses to Social Mobility and Educational Opportunity. Academic Press, Orlando, FL.

Khandke, V., Pollitt, E., Gorman, K., 1999. The role of maternal literacy in child health and cognitive development in rural Guatemala. Poster presented at the biennial meetings of the Society for Research in Child Development, April, 1999

Kirsch, I., Jungeblut, A., 1986. Literacy: Profiles of America's Young Adults. Educational Testing Service, Princeton, NJ.

Kirsch, I., Jenkins, L., Jungeblut, A., Kolstad, A., 1993. Adult Literacy in America: A First Look at the Results of the National Adult Literacy Survey. National Center for Educational Statistics, Washington, DC.

LeVine, R.A., LeVine, S., Richman, A., Tapia Uribe, M.F., Sunderland Correa, C., Miller, P., 1991. Women's schooling and child care in the demographic transition: a Mexican case study. Population and Development Review 17, 459-496.

LeVine, R.A., Dexter, E., Velasco, P., LeVine, S., Joshi, A., Stuebing, K., Tapia Uribe, M.F., 1994. Maternal literacy and health care in three countries: a preliminary report. Health Transition Review 4, 186-191.

LeVine, R.A., LeVine, S., Schnell, B., 2001. Improve the women: Mass schooling, female literacy and worldwide social change. Harvard Educational Review 71, 1-50.

LeVine, R.A., LeVine, S.E., Rowe, M.L., Schnell-Anzola, B., 2004. Maternal literacy and health behavior: a Nepalese case study. Social Science and Medicine 58 (4), 863-877.

Mayer, P., 1999. India's falling sex ratios. Population and Development Review 25, 323-343.

Méndez Castellanos, H., 1996. Estudio nacional de crecimiento y desarrollo humano de la República de Venezuela [National study of growth and human development in the Republic of Venezuela], Tomo II. Fundacredesa, Caracas.

Moseley, H., Chen, L. (Eds.), 1984. Child Survival: Strategies for Research. Population and Development Review, Vol. 10 (Suppl.) 1-400.

Nuñez, M., 1993. La planificación familiar no ha tenido impacto en el país [Family planning has had no impact in Venezuela]. El Nacional, 23-07, C/2.

OCEI, 1998. Anuario Estadístico de Venezuela 1997. División de Publicaciones y Artes Gráficas de la Oficina Central de Estadística e Informática (OCEI), Caracas. 
OECD/Statistics Canada, 1995. Literacy, Economy and Society: Results of the First International Adult Literacy Survey. OECD, Paris.

Risk, M., 1993. En 7 centímetros se redujo tamaño de los niños a causa de la pobreza. [The mean height of the children has decreased by $7 \mathrm{~cm}$ due to poverty]. El Nacional, 28-10, s/r.

Snow, C.E., 1990. The development of definitional skill. Journal of Child Language 17, 697-710.

Snow, C.E., Burns, S., Griffin, P. (Eds.), 1998. Preventing Reading Difficulties in Young Children. National Academy Press, Washington, DC.

Stuebing, K., 1997. Maternal schooling and comprehension of child health information in urban Zambia: is literacy a missing link in the maternal schooling-child health relationship?. Health Transition Review 7, 151-172.

Thomas, D., 1999. Fertility, education and resources in South Africa. In: Bledsoe, C., Casterline, J.B., Johnson-Kuhn, J.A., Haaga, J.G. (Eds.), Critical Perspectives on Schooling and Fertility in the Developing World. National Academy Press, Washington, DC.
UNICEF, 1998. The State of the World's Children 1999. New York.

Valdes, G., Geoffrion-Vinci, M., 1998. Chicano Spanish: the problem of the "under developed" code in bilingual repertoires. Modern Language Journal 82, 473-501.

Venegas, V.M., 1993. El significado de la escuela en familias pobres. [What going to school means to poor families]. Unpublished masters thesis: Universidad Central de Venezuela (UCD, Caracas Venezuela).

Wagner, D., 1995. Literacy and development: rationales myths, innovations and future directions. International Journal of Educational Development 15, 341-362.

Wagner, D., 2000. Literacy and adult education. EFA 2000 Thematic Study for presentation at the World Education Forum, Dakar, April 2000. International Literacy Institute, University of Pennsylvania.

Wagner, D., Venezky, R., Street, B. (Eds.), 1999. Literacy: An International Handbook. Westview Press, Boulder, CO.

Wells, G., 1999. Dialogic Inquiry: A Sociocultural Practice and Theory of Education. Cambridge University Press, New York. 